\title{
Dehydroaromatization of methane over noble metal loaded Mo/ H-ZSM-5 zeolite catalysts
}

\author{
Themba E. Tshabalala ${ }^{1}$ (D) Neil J. Coville ${ }^{2}$ D . James A. Anderson ${ }^{3} \cdot$ Michael S. Scurrell $^{4}$ D
}

Received: 27 November 2020 / Accepted: 22 April 2021 / Published online: 3 May 2021

(c) The Author(s) 2021

\begin{abstract}
Dehydroaromatization of methane (MDA) reaction was investigated over platinum modified Mo/H-ZSM-5 catalysts which were pre-carbided at $750{ }^{\circ} \mathrm{C}$. The influence of platinum on the catalytic performance and product selectivity of Mo/H-ZSM-5 catalysts for the MDA reaction at $700{ }^{\circ} \mathrm{C}$ were studied. The presence of platinum led to a slight decrease in methane conversion from 7.5 to $4.2 \%$. Aromatic selectivities above $90 \%$ were obtained with catalysts containing low platinum loadings ( 0.5 and $1.0 \mathrm{wt} . \%)$, with benzene being the most prominent product. A decrease in coke selectivity and coke deposits was noted with the platinum modified Mo/H-ZSM-5 zeolite catalysts. A comparative study was performed to compare platinum, palladium and ruthenium promoted Mo/H-ZSM-5 zeolite catalysts with un-promoted Mo/H-ZSM-5. The ruthenium promoted catalyst proved to be superior in catalytic performance, with a higher methane conversion obtained than that found for platinum promoted and palladium promoted Mo/H-ZSM- 5 catalysts. Benzene selectivity of about $60 \%$ was obtained for ruthenium and palladium promoted Mo/H- ZSM-5 catalysts and the total aromatic selectivity was maintained at $90 \%$. TGA results showed a total reduction of $50 \%$ by weight of carbon deposited on the promoted Mo/H-ZSM- 5 catalyst.
\end{abstract}

\section{Graphic abstract}
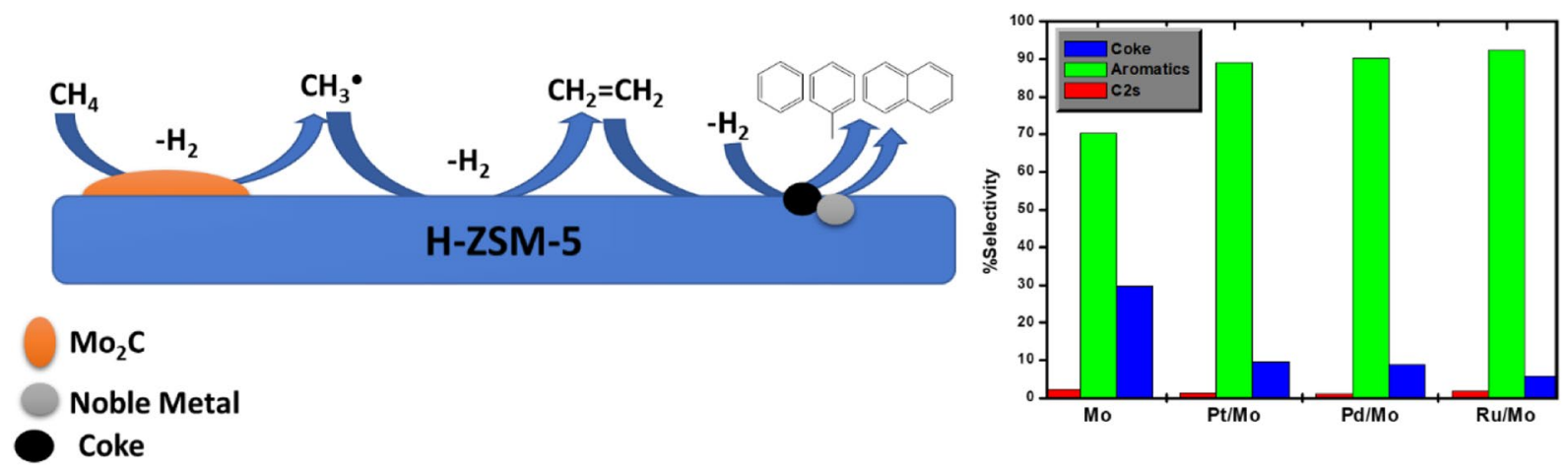

Keywords Dehydroaromatization $\cdot$ Methane $\cdot \mathrm{H}-\mathrm{ZSM}-5 \cdot$ Molybdenum $\cdot$ Platinum $\cdot$ PGMs

Themba E. Tshabalala

themba.tshabalala@spu.ac.za

1 School of Natural and Applied Sciences, Sol Plaatje University, Private Bag X 5008, Kimberley 8300,

South Africa

2 Molecular Sciences Institute, School of Chemistry, University of the Witwatersrand, Johannesburg 2050, South Africa
3 Surface Chemistry and Catalysis Group, Department of Chemistry, University of Aberdeen, Meston Walk, Aberdeen AB24 3UE, Scotland, UK

4 Department of Civil and Chemical Engineering, University of South Africa, Florida, Johannesburg 1710, South Africa 


\section{Introduction}

The demand for highly marketable products from refineries has grown and this has put pressure on the effective utilization of fossil fuel sources and low valued hydrocarbons. The abundance and lower cost of natural gas have generated extraordinary interest in transforming methane into valuable compounds. The conversion of methane into syngas through auto-reform has greatly contributed to the petroleum industry. The methane dehydroaromatization $(\mathrm{MDA})\left[6 \mathrm{CH}_{4(\mathrm{~g})} \rightarrow \mathrm{C}_{6} \mathrm{H}_{6(\mathrm{~g})}+9 \mathrm{H}_{2(\mathrm{~g})} \Delta \mathrm{G}^{\mathrm{o}}=+433 \mathrm{~kJ} \mathrm{mo}\right.$ $\left.\mathrm{l}^{-1} \quad \Delta \mathrm{H}^{\mathrm{o}}=+531 \mathrm{~kJ} \mathrm{~mol}^{-1}\right]$ has presented an alternative pathway for the generation of benzene and hydrogen, with the former being useful in paint, polymer, pharmaceutical, and the latter could be used in fuel cell applications.

Since the discovery of methane aromatization using molybdenum modified H-ZSM-5 zeolite catalysts at $700{ }^{\circ} \mathrm{C}$ by Wang [1] many papers on the catalytic activity, reaction mechanism and catalyst characterization of the reaction have been published [2-8]. Various bifunctional catalysts with different transition metal ions Mn [9], W [10], Ga [11] and Fe [12] supported on H-ZSM-5 zeolites were investigated, however, molybdenum supported catalysts have shown better methane conversion and high aromatic selectivity. Solymosi et al. [13, 14] investigated the interaction of methane with various supported and unsupported molybdenum species (i.e. $\mathrm{Mo}, \mathrm{MoO}_{2}, \mathrm{MoO}_{3}, \mathrm{Mo}_{2} \mathrm{C}$ and $\mathrm{MoC}_{1-x}$ ) that might be present during the methane aromatization at $700{ }^{\circ} \mathrm{C}$. The results presented in their papers showed the formation of ethane, ethylene and benzene on the supported catalysts. The post-reaction analysis using XPS revealed the presence of molybdenum carbides and unreduced $\mathrm{Mo}^{4+}$ and $\mathrm{Mo}^{5+}$ species formed during the catalytic reaction. They also suggested that $\mathrm{Mo}_{2} \mathrm{C}$ is the active surface species in the Mo-containing catalysts. The Jiang group [15] studied the formation of molybdenum carbide during the aromatization of methane, which they referred to as the induction period. The Lunsford group [16-19] carried out some work using XPS to characterize $\mathrm{Mo} / \mathrm{H}-$ ZSM-5 catalysts during the methane dehydroaromatization (MDA) reaction. Their results indicated a gradual reduction of $\mathrm{Mo}^{6+}$ species to lower oxidation state molybdenum species ${ }^{\circ} \mathrm{C}$ curring with reaction time leading to the formation of molybdenum carbide species. The formation of the molybdenum carbide species within the channels and pores of the zeolites is considered as an induction period. Ha et al. [20] and Tan et al. [21] have drawn some conclusions and proposed that the formation of molybdenum carbide or oxycarbide from the reduction of MoOx with methane is responsible for the activation and conversion of methane into $\mathrm{C}_{2}$ intermediates, which are then transformed into aromatic compounds, mainly benzene. Based on the induction period reaction studies, they proposed that coke-modified $\mathrm{Mo}_{2} \mathrm{C}$ surface species are the active sites responsible for the formation of ethylene rather than the clean $\mathrm{Mo}_{2} \mathrm{C}$ surface. Ma et al. [22] concluded that the activation of methane was the crucial step in the MDA reaction. Regarding catalytic activity, there are terminal drawbacks associated with carbonaceous deposits forming on the catalyst active sites leading to a shortened catalyst life cycle and rapid catalyst deactivation. The addition of a second metal to $\mathrm{Mo} / \mathrm{H}-\mathrm{ZSM}-5$ could have a positive effect on the activity, selectivity and catalyst deactivation rate [3]. For instance, the addition of cobalt or iron to a Mo/H-ZSM-5 zeolite catalyst effectively enhanced the catalytic stability in the presence of $\mathrm{CO}_{2}$ [23-25]. Metals such as $\mathrm{Cu}$ [15], $\mathrm{Zr}$ and $\mathrm{W}$ [2] improved the catalytic activity and selectivity to aromatics. Shu et al. [26] studied the effect of ruthenium on the catalyst characteristics of Mo/H-ZSM-5. Their results showed that the addition of ruthenium decreased the concentration of Brønsted acid sites and increased the concentration of weak acid sites. On the other hand, the presence of ruthenium led to the generation of medium acid sites. However, all secondary metals added will have a positive effect on the catalytic activity and selectivity of Mo/H-ZSM-5. For example, the presence of lithium [27], phosphorus [27] or vanadium [2] to the Mo/H-ZSM-5 zeolite catalyst was found to produce a low catalytic activity and this was attributed to a decrease in the concentration of Brønsted acid sites. The difference between the $\mathrm{Ru}$ and other metals is that ruthenium facilitates the hydrogenolysis of carbon and this led to reduction of coke deposits and improves the catalytic activity by reducing the amount of coke deposit generated during the reaction. The presence of noble metals also facilitates the formation of $\alpha-\mathrm{Mo}_{2} \mathrm{C}$ which is regarded to be more stable than $\beta-\mathrm{Mo}_{2} \mathrm{C}[7,28]$.

The bimetallic noble metal-containing catalyst systems have attracted much attention in catalysis. The noble metal and secondary metal interaction change both the catalytic and chemisorptive properties of both the noble metal and the secondary metal added to the catalysts. In this paper, we have focused on the effect of platinum on the catalytic properties of Mo/H-ZSM- 5 zeolite catalyst at low molybdenum loadings (i.e. $2 \mathrm{wt} \% \mathrm{Mo}$ ). The ex-situ carburization of a Mo/H-ZSM-5 catalyst was performed at $750{ }^{\circ} \mathrm{C}$ prior to addition of platinum. The Pt-Mo interaction was studied at low platinum loadings, from 0.5 to $2 \mathrm{wt} . \%$, using infrared spectroscopy with $\mathrm{CO}$ as the probe molecule. Furthermore, the effect of platinum on the catalytic activity of methane aromatization was performed at $700{ }^{\circ} \mathrm{C}$ for $7 \mathrm{~h}$ and the influence of platinum on coke suppression during the reaction was analyzed by TGA. The effect of other noble metals (i.e. palladium and ruthenium) on the MDA over Mo/H-ZSM-5 was investigated for comparison purpose. 


\section{Experimental}

\section{Chemicals used}

Ammonium heptamolybdate (99.98\% purity, Saarchem), dihydrogen hexachloroplatinate (99.8\% purity, Impala Platinum), and methane gas ( $90 \% \mathrm{CH}_{4}$, balance argon, Afrox) were used as purchased.

\section{Catalyst preparation}

The preparation of $\mathrm{MoO}_{3} / \mathrm{H}-\mathrm{ZSM}-5$ catalyst was achieved by the incipient wetness impregnation of H-ZSM-5 zeolite $\left(\mathrm{SiO}_{2} / \mathrm{Al}_{2} \mathrm{O}_{3}=70 ; 66 \%\right.$ XRD crystallinity relative to a highly crystalline reference sample) with an aqueous solution of ammonium heptamolybdate, $\left[\left(\mathrm{NH}_{4}\right)_{6} \mathrm{Mo}_{7} \mathrm{O}_{24} \cdot 4 \mathrm{H}_{2} \mathrm{O}\right]$ to achieve $2 \mathrm{wt} \%$ Mo loading. The sample was dried at $120{ }^{\circ} \mathrm{C}$ for $16 \mathrm{~h}$ and then calcined at $500{ }^{\circ} \mathrm{C}$ for $6 \mathrm{~h}$. The $\mathrm{Mo}_{2} \mathrm{C} / \mathrm{H}-\mathrm{ZSM}-5$ samples were prepared by heating $\mathrm{MoO}_{3} / \mathrm{H}-\mathrm{ZSM}-5$ sample under a flow of $\mathrm{CH}_{4} / \mathrm{H}_{2}$ from room temperature to $750{ }^{\circ} \mathrm{C}$ at a $10^{\circ} \mathrm{C} / \mathrm{min}$ heating rate and held at $750{ }^{\circ} \mathrm{C}$ for $1 \mathrm{~h}$. The samples were allowed to cool to room temperature under a flow of nitrogen. Subsequently, platinum was loaded on $\mathrm{MoO}_{3} / \mathrm{H}-\mathrm{ZSM}-5$ samples by an impregnation method with a solution of dihydrogen hexachloroplatinate, $\left[\mathrm{H}_{2} \mathrm{PtCl}_{6}\right]$ of appropriate concentrations. The samples were dried at $120{ }^{\circ} \mathrm{C}$ overnight and then calcined at $500{ }^{\circ} \mathrm{C}$ for $6 \mathrm{~h}$. The platinum loadings were kept between 0.5 and 2.0 wt. $\%$.

\section{Catalyst characterization}

\section{BET surface area and pore volume}

These were determined using an ASAP-2000 Tristar Micromeritics 3300 series instrument. About $0.20 \mathrm{~g}$ of a sample was degassed at $400{ }^{\circ} \mathrm{C}$ for $4 \mathrm{~h}$ prior to nitrogen exposure at $-196{ }^{\circ} \mathrm{C}$.

\section{Carbon monoxide adsorption: Fourier transform infrared (FT-IR) spectroscopy}

The FT-IR spectra were recorded using a PerkinElmer 100 spectrometer operating with a resolution of $4 \mathrm{~cm}^{-1}$. Selfsupporting discs of $16 \mathrm{mmin}$ diameter, and weighing about $40 \mathrm{mg}$ were prepared by applying 3 tons pressure to the powder sample between two stainless steel dies. The discs were then suspended in a quartz disc holder and mounted in an IR cell connected to a vacuum line. Prior to adsorption measurements, the discs were heated to $400{ }^{\circ} \mathrm{C}$ in nitrogen for $1 \mathrm{~h}$ and evacuated to a pressure of $c a 3 \times 10^{-3}$ mbar for
$1 \mathrm{~h}$. The IR CO adsorption measurements were performed at $\mathrm{CO}$ pressures between 1 and 50 Torr with the sample at a beam temperature of $c a .25{ }^{\circ} \mathrm{C}$. The IR spectra were recorded $15 \mathrm{~min}$ after exposure to $\mathrm{CO}$.

\section{Pulse CO chemisorption}

Carbon monoxide chemisorption experiments were carried out using a Micromeritics Autochem 2910 instrument. All catalysts were reduced at $200{ }^{\circ} \mathrm{C}$ in a hydrogen mixture $(5 \%$ $\mathrm{H}_{2}$, balance $\mathrm{Ar}$ ) for $1 \mathrm{~h}$ to selectively reduce platinum oxide species present in the catalysts. The pulsing experiments were carried out using a $404 \mu \mathrm{L}$ sample loop filled with a mixture of carbon monoxide and helium $(5 \% \mathrm{CO}$, balance $\mathrm{He}$ ) being injected onto the sample which was held at $50{ }^{\circ} \mathrm{C}$ in helium. The percentage of metal dispersion was calculated from the $\mathrm{CO}$ uptake assuming a $\mathrm{CO} / \mathrm{Pt}$ stoichiometry of 1 . The stoichiometry ratio was based on the FT-IR spectra of adsorbed CO which showed only a linear species [29, 30].

\section{TGA measurements of coked catalysts}

These were performed using a TGA-4000 (Perkin Elmer) analyzer using Pyris software. These experiments were performed under an air atmosphere to quantify the amount of coke deposited on the catalyst during the MDA reaction. About $10 \mathrm{mg}$ of the catalyst was placed in a sample holder and the airflow adjusted to $20 \mathrm{~mL} / \mathrm{min}$. The sample was heated from 35 to $900{ }^{\circ} \mathrm{C}$ at a rate of $10{ }^{\circ} \mathrm{C} / \mathrm{min}$.

\section{Catalytic evaluation}

The direct conversion of methane was carried out in a fixedbed quartz tubular reactor at atmospheric pressure. $0.50 \mathrm{~g}$ of catalyst was loaded in a reactor and pretreated at $700{ }^{\circ} \mathrm{C}$ for $1 \mathrm{~h}$ under a flow of nitrogen. A gas mixture $\left(90 \% \mathrm{CH}_{4}\right.$, balance Ar) was then introduced at a flow rate of $13.5 \mathrm{~mL} /$ $\min (\mathrm{WHSV}=1620 \mathrm{~mL} / \mathrm{g}$.cat.h). The exit stream was analyzed using an online gas chromatograph (GC) equipped with Porapak Q and Carboxen-1000 columns coupled to an FID and TCD, respectively. The GC traces were monitored by a computer equipped with Clarity software. Methane conversion and product selectivity were calculated on a carbon number basis and coke selectivity was accounted for. The mole fraction of each component both in the inlet and outlet is represented by $X_{i}, N_{i}$ is the carbon number of product being formed and $\% S_{i}$ represents the product selectivity.

$\%$ Conversion $=\left(1-\frac{X_{C H 4}^{\text {out }} \times X_{A r}^{\text {in }}}{X_{\mathrm{CH} 4}^{\text {in }} \times X_{A r}^{\text {out }}}\right) \times 100 \%$.

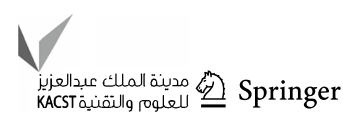




$$
\begin{aligned}
& \% S_{i}=\frac{X_{A r}^{\mathrm{in}} \times X_{i}^{\mathrm{out}} \times N_{i}^{\mathrm{carbon}}}{X_{A r}^{\mathrm{out}} \times X_{\mathrm{CH} 4}^{\mathrm{in}}-X_{A r}^{\mathrm{in}} \times X_{\mathrm{CH} 4}^{\mathrm{out}}} \times 100 \% \\
& \% S_{\text {coke }}=100 \%-\sum_{n} \% S_{i}
\end{aligned}
$$

\section{Results and discussion}

\section{Characterization results}

The influence of platinum on the surface area properties of Mo/H-ZSM-5 zeolite catalysts was investigated by nitrogen adsorption studies. The BET surface areas and pore volume results of platinum modified Mo/H-ZSM-5 zeolite catalyst are shown in Table 1.

The results show an insignificant decrease in BET surface area and pore volume with an increase in platinum loading from 0 to $1 \mathrm{wt} . \%$. A noticeable decrease in surface area from 380 to $360 \mathrm{~m}^{2} / \mathrm{g}$ is observed when increasing the platinum content to $2 \mathrm{wt} . \%$ loading. The decrease in surface area may be associated with the location of metal particles on/in the zeolite. These results suggest that the platinum species are too small to modify structural (i.e. surface and pores) properties of the H-ZSM-5 zeolite; if the metal particles are located in the pores of the zeolites they show an insignificant effect on the surface area [31, 32]. The XRD results illustrated the same intensity for all samples, which implies that the structure of H-ZSM-5 zeolite remained intact after Mo and Pt impregnation (Fig. 1).

The effect of platinum on the acid site distribution was investigated using the ammonia desorption technique. The $\mathrm{NH}_{3}$-TPD profiles of the parent H-ZSM-5, 2Mo/H-ZSM-5 and platinum impregnated $2 \mathrm{Mo} / \mathrm{H}-\mathrm{ZSM}-5$ zeolite catalysts are shown in Fig. 2. The profiles exhibit two well-defined peaks (at $183{ }^{\circ} \mathrm{C}$ and $438{ }^{\circ} \mathrm{C}$ ), designated as the low temperature (LT) peak and the high temperature (HT) peak respectively. Wang et al. [33] and Hidalgo et al. [34] suggested that if the ammonia desorption peak temperature is

Table 1 Nitrogen adsorption (BET) results of $\mathrm{Pt}$ loaded $\mathrm{Mo} / \mathrm{H}-$ ZSM-5 zeolite catalysts

\begin{tabular}{lll}
\hline Catalysts & Surface area $(\mathrm{m} 2 / \mathrm{g})$ & $\begin{array}{l}\text { Pore } \\
\text { volume } \\
(\mathrm{cm} 3 / \mathrm{g})\end{array}$ \\
\hline $2 \mathrm{Mo} / \mathrm{H}-\mathrm{ZSM}-5$ & 385 & 0.248 \\
$0.5 \mathrm{Pt} / 2 \mathrm{Mo} / \mathrm{H}-\mathrm{ZSM}-5$ & 381 & 0.247 \\
$1 \mathrm{Pt} / 2 \mathrm{Mo} / \mathrm{H}-\mathrm{ZSM}-5$ & 380 & 0.246 \\
$2 \mathrm{Pt} / 2 \mathrm{Mo} / \mathrm{H}-\mathrm{ZSM}-5$ & 362 & 0.237 \\
$2 \mathrm{Pt} / \mathrm{H}-\mathrm{ZMS}-5$ & 380 & 0.237 \\
\hline
\end{tabular}

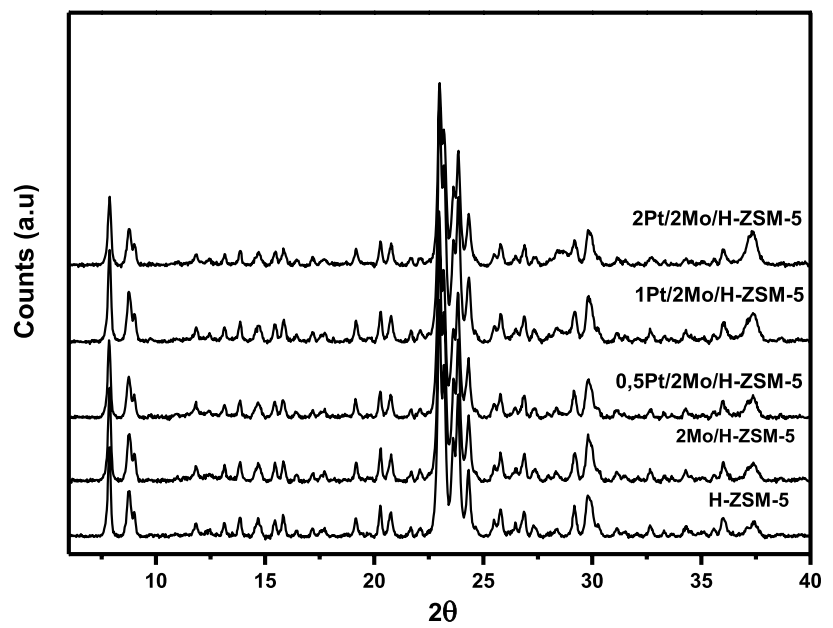

Fig. 1 XRD patterns of H-ZSM-5, Mo/H-ZSM-5 and Pt modified $\mathrm{Mo} / \mathrm{H}-\mathrm{ZSM}-5$ zeolites catalysts

above $350{ }^{\circ} \mathrm{C}$, the peak represents the desorption of ammonia from the strong acid sites. In contrast, the peaks with desorption temperature below $350{ }^{\circ} \mathrm{C}$ represent desorption of ammonia from weak acid sites. A decrease in the intensity of the HT peak at $438^{\circ} \mathrm{C}$ was observed after the H-ZSM-5 was impregnated with a molybdenum precursor solution

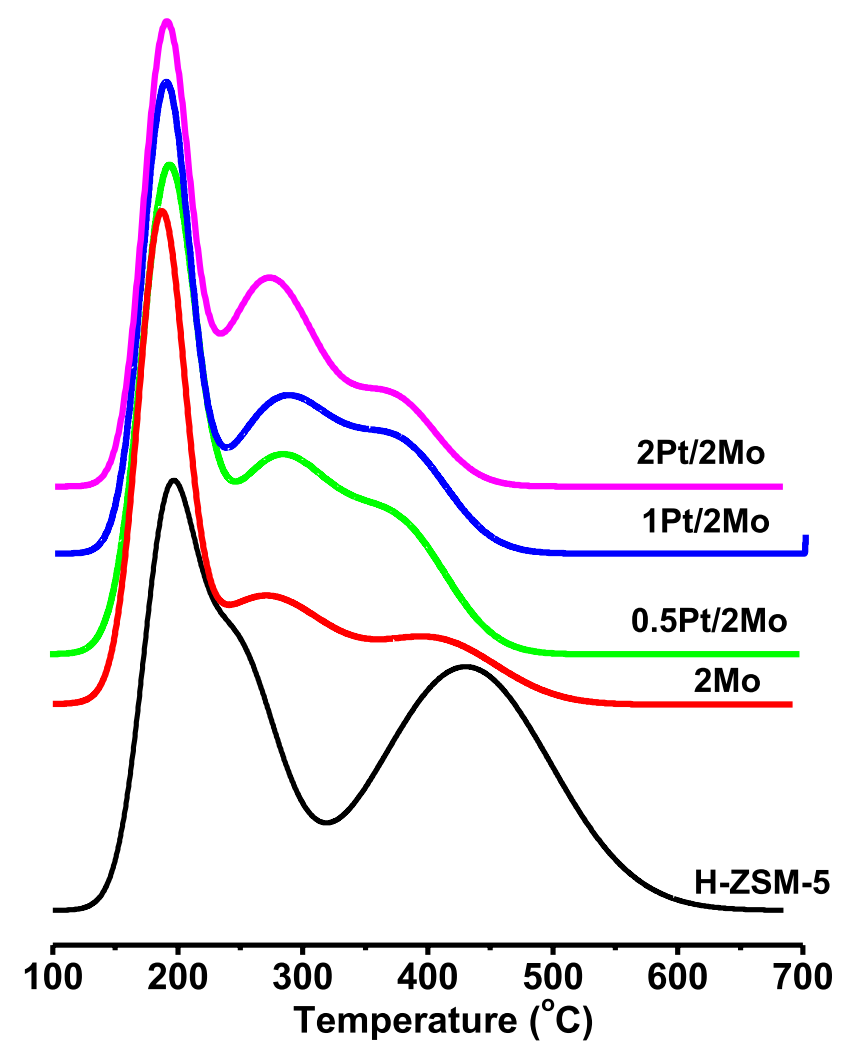

Fig. 2 NH3-TPD profiles of the parent H-ZSM-5, 2Mo/H-ZSM-5 and $\mathrm{Pt} / 2 \mathrm{Mo} / \mathrm{H}-\mathrm{ZSM}-5$ zeolite catalysts with various platinum loadings 
followed by calcination at $500{ }^{\circ} \mathrm{C}$. This decrease is associated with the migration of molybdenum oxide species inside the zeolite channels. The Mo anchor on the acid sites leading to a decrease in the concentration of Brønsted acid sites. The addition of platinum led to a decrease in the peak intensity and the desorption temperature of the HT peak which shifted to a lower temperature $\left(400{ }^{\circ} \mathrm{C}\right)$. There is a third desorption peak at $260{ }^{\circ} \mathrm{C}$, which is associated with medium acid sites generated by the presence of platinum. When the platinum loading was increased an increase in the concentration of medium acid sites was observed. This suggests that as the metal content increases the generation of medium acid sites is more pronounced. This decrease in the HT peak intensity may be attributed to the metal interaction with the bridging hydroxyl group acting as Brønsted acid sites. Thus, we observed a decrease in the Brønsted acid sites concentration as the total metal content increased.

To obtain more information about the platinum species or oxidation states of the metals present in the catalysts, $\mathrm{CO}$ adsorption experiments were performed on both the nitrogen treated and reduced catalysts. The IR spectra were recorded at room temperature after 15-min intervals of $\mathrm{CO}$ adsorption and the $\mathrm{CO}$ pressure was varied from 1 to
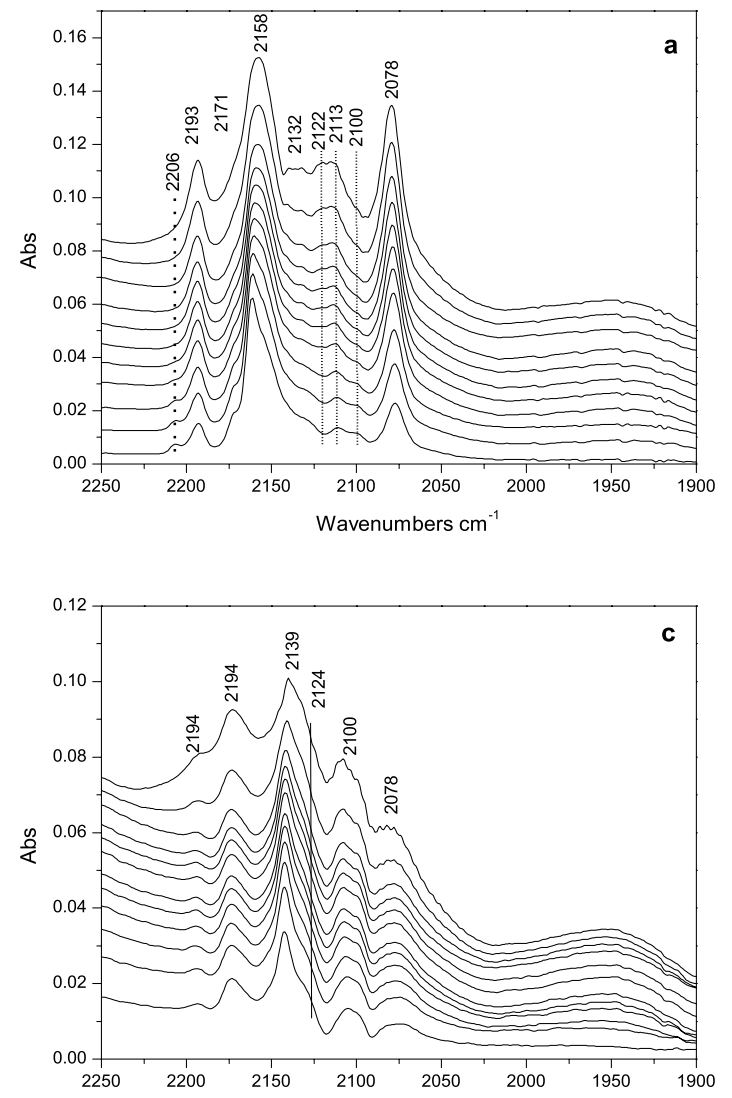

55 Torr. The results of $\mathrm{CO}$ adsorption of the $2 \mathrm{Pt} / \mathrm{H}-\mathrm{ZSM}-5$, $0.5 \mathrm{Pt} / 2 \mathrm{Mo} / \mathrm{H}-\mathrm{ZSM}-5,1 \mathrm{Pt} / 2 \mathrm{Mo} / \mathrm{H}-\mathrm{ZSM}-5$ and $2 \mathrm{Pt} / 2 \mathrm{Mo} / \mathrm{H}-$ ZSM-5 zeolite catalysts are presented in Fig. 3. The IR spectra of Pt/H-ZSM-5 catalyst show several bands $(2207,2193$, $2171,2158,2132,2122,2113,2100$ and $\left.2078 \mathrm{~cm}^{-1}\right)$. The intensities of the two bands at 2206 and $2171 \mathrm{~cm}^{-1}$ changed concurrently, which suggest they are associated with one platinum species. When CO pressure is increased these bands disappeared without generating any new bands. Chakarova et al. [35-37] observed similar results in the study of polycarbonyl species in a Pt/H-ZSM-5 zeolite catalyst. They observed similar bands at 2212 and $2176 \mathrm{~cm}^{-1}$ and they attributed them to dicarbonly complexes of $\mathrm{Pt}^{3+}$ (i.e. a $\mathrm{Pt}^{3+}(\mathrm{CO})_{2}$ complex) which decomposed without generating any $\mathrm{Pt}^{3+}$ monocarbonyl complex. This suggests that at high CO pressure the $\mathrm{Pt}^{3+}$ which is considered to be one of the less stable oxidation states of platinum is reduced to lower oxidation states of platinum. The IR spectra also showed two major bands with high intensities at 2158 and $2078 \mathrm{~cm}^{-1}$. The band at $2158 \mathrm{~cm}^{-1}$ is due to the $\mathrm{CO}$ on $\mathrm{Pt}^{2+}$ species forming a monocarbonyl complex [38]. This band was initially at $2161 \mathrm{~cm}^{-1}$ at low CO pressures and as the CO pressure increased the band shifted to lower wavenumbers
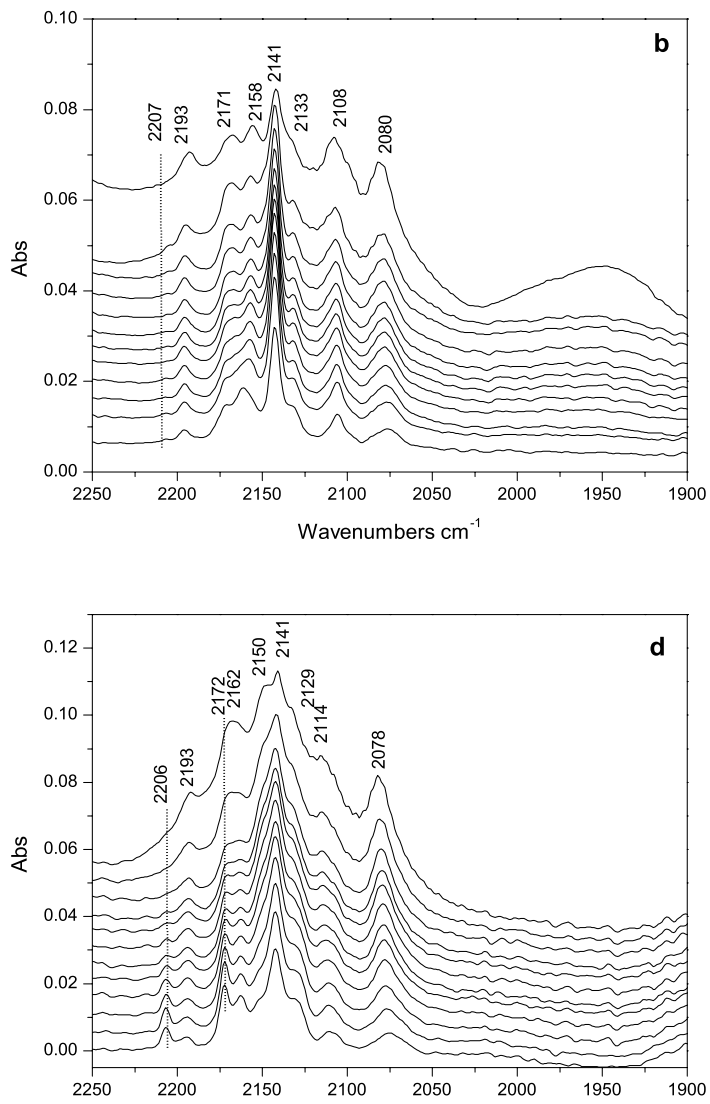

Fig. 3 Adsorption of $\mathrm{CO}$ on platinum loaded samples at different $\mathrm{CO}$ pressures. a 2Pt/H-ZSM-5, b 0.5Pt/2Mo/H-ZSM-5, c $1 \mathrm{Pt} / 2 \mathrm{Mo} / \mathrm{H}-\mathrm{ZSM}-5$ and $\mathbf{d} 2 \mathrm{Pt} / 2 \mathrm{Mo} / \mathrm{H}-\mathrm{ZSM}-5$ 
(i.e. below $2158 \mathrm{~cm}^{-1}$ ). The band at $2078 \mathrm{~cm}^{-1}$ is due to the adsorption of $\mathrm{CO}$ on metallic platinum species [39, 40]. The intensity of both bands increased with increase in $\mathrm{CO}$ pressure. The $\mathrm{CO}$ molecules adsorbed on small platinum particles ${ }^{\circ} \mathrm{C}$ curred with low energy stretching frequencies [40-42]. This led the authors to assign bands at 2113 and $2100 \mathrm{~cm}^{-1}$ to $\mathrm{CO}$ adsorbed on $\mathrm{Pt}^{2+}$ and $\mathrm{Pt}^{0}$ species respectively, even though the band intensities were low. The band at $2100 \mathrm{~cm}^{-1}$ has been previously assigned to $\mathrm{CO}$ adsorbed on small (i.e. 2-3.5 nm) platinum particles [43]. However, this band tends to disappear with an increase in CO pressure. The band at $2193 \mathrm{~cm}^{-1}$ has been assigned to $\mathrm{CO}$ being adsorbed on $\mathrm{Pt}^{3+}$ species forming a monocarbonyl complex [44]. The IR bands associated with CO adsorbed on $\mathrm{Pt}^{2+}$ species shifted to lower wavenumbers. Other bands developed due to the presence of the molybdenum species. The band at $2158 \mathrm{~cm}^{-1}$ observed during $\mathrm{CO}$ adsorption on Pt/H-ZSM-5 shifted to $2141 \mathrm{~cm}^{-1}$ when CO was adsorbed on the molybdenum-containing samples and a new band at $2162 \mathrm{~cm}^{-1}$ was also observed. The band at $2162 \mathrm{~cm}^{-1}$ is attributed to $\mathrm{CO}$ adsorbed on molybdenum species and it is more noticeable in a $1 \mathrm{Pt} / 2 \mathrm{Mo} / \mathrm{H}-\mathrm{ZSM}-5$ sample. According to several authors, this band may be attributed to the adsorption of $\mathrm{CO}$ on $\mathrm{Mo}^{4+}$ [45-47]. However, the adsorption of CO on platinum-free Mo/H-ZSM-5 samples showed no band (at $2160 \mathrm{~cm}^{-1}$ region) of the $\mathrm{CO}$ adsorbed on the molybdenum species (Fig. 4). Studies of $\mathrm{CO}$ adsorbed on the 2Mo/H-ZSM-5 sample showed no bands of $\mathrm{CO}$ adsorbed on a molybdenum carbide surface. This was verified by increasing the concentration of molybdenum carbide from 2 to 15 wt.\% loading; no significant change was observed in the $\mathrm{CO}$ adsorption part of the IR spectrum. However, some work has been reported on the adsorption of $\mathrm{CO}$ on molybdenum carbide on different supports, which were pre-carbided insitu. Two bands at 2175 and $2050 \mathrm{~cm}^{-1}$ were observed and the band at $2050 \mathrm{~cm}^{-1}$ shifted depending on the support used in the study. The bands were attributed to two kinds of molybdenum species that may be present in the catalyst. Several researchers reported $\mathrm{CO}$ adsorption on $\mathrm{Mo}^{4+}$ and $\mathrm{Mo}^{2+}$ at 2175 and $2050 \mathrm{~cm}^{-1}$ respectively. DeCanio and Storm [48] did some $\mathrm{CO}$ adsorption studies on $\mathrm{Mo}_{2} \mathrm{C} / \mathrm{Al}_{2} \mathrm{O}_{3}$ and observed these bands at 2178 and $2060 \mathrm{~cm}^{-1}$. Rasko and Kiss [49] studied the $\mathrm{CO}$ adsorption on $\mathrm{Mo}_{2} \mathrm{C} / \mathrm{SiO}_{2}$ and observed a band at $2079 \mathrm{~cm}^{-1}$ and they ascribed this band to $\mathrm{CO}$ adsorption on $\mathrm{Mo}^{2+}$.

The influence of the platinum loading on the amount of $\mathrm{CO}$ adsorbed was further studied using a $\mathrm{CO}$ pulse chemisorption technique. The platinum loaded Mo/H-ZSM-5 catalysts were reduced at $200{ }^{\circ} \mathrm{C}$ for $1 \mathrm{~h}$ and the $\mathrm{CO}$ uptake results are presented in Table 2.

The results show that large amounts (i.e. $6.18 \mu \mathrm{mol} / \mathrm{g}$ ) of $\mathrm{CO}$ were adsorbed on the molybdenum free $2 \mathrm{Pt} / \mathrm{H}-\mathrm{ZSM}-5$ catalysts and catalysts with molybdenum gave a decrease in the amount of $\mathrm{CO}$ uptake with an increase in platinum loading from 1.45 to $3.99 \mu \mathrm{mol} / \mathrm{g}$ of $\mathrm{CO}$. The $0.5 \mathrm{Pt} / 2 \mathrm{Mo} / \mathrm{H}-$ ZSM-5 catalyst gave the least $\mathrm{CO}$ uptake and $2 \mathrm{Pt} / 2 \mathrm{Mo} / \mathrm{H}-$ ZSM-5 catalyst the most. Relatively low amounts of $\mathrm{CO}$ uptake were observed with catalysts containing both

Table $2 \mathrm{CO}$ Chemisorption on $\mathrm{Pt} / \mathrm{Mo} / \mathrm{H}-\mathrm{ZSM}-5$ zeolite samples reduced at $200 \mathrm{oC}$ for $1 \mathrm{~h}$

\begin{tabular}{llc}
\hline Catalysts & $\begin{array}{l}\text { CO uptake } \\
(\mu \mathrm{mol} / \mathrm{g})\end{array}$ & Dispersion $(\%)$ \\
\hline 2Mo/H-ZSM-5 & - & - \\
$0.5 \mathrm{Pt} / 2 \mathrm{Mo} / \mathrm{H}-Z S M-5$ & 1.45 & 0.86 \\
1Pt/2Mo/H-ZSM-5 & 2.58 & 4.20 \\
$2 \mathrm{Pt} / 2 \mathrm{Mo} / \mathrm{H}-Z \mathrm{ZSM}-5$ & 3.99 & 7.78 \\
$2 \mathrm{Pt} / \mathrm{H}-\mathrm{ZMS}-5$ & 6.18 & 24.1 \\
\hline
\end{tabular}

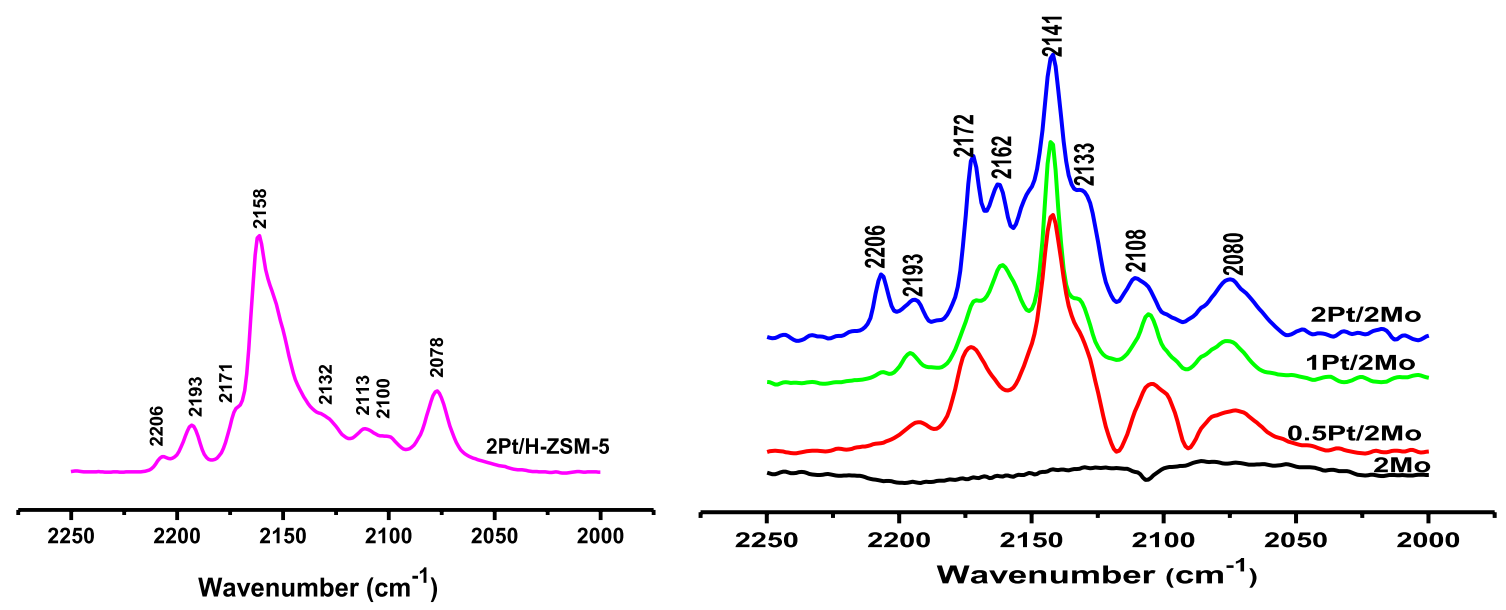

Fig. 4 IR spectra of CO adsorption on 2Mo/H-ZSM-5 and Pt/Mo/H-ZSM-5 zeolite catalysts with various platinum loadings take at 5 Torr CO pressure 
molybdenum and platinum when compared with the $2 \mathrm{Pt} / \mathrm{H}$ ZSM-5 catalyst. The amount of $\mathrm{CO}$ adsorbed is associated with the number of platinum species in the metallic state available to bond with $\mathrm{CO}$ molecules. The decrease in $\mathrm{CO}$ uptake may therefore suggest that during the reduction step molybdenum species migrate to the large platinum particles and form a mixed oxide surface layer that is inactive to chemically adsorb $\mathrm{CO}$ [50]. It might also be due to the electronic effects contributed by molybdenum that weaken the CO-Pt interaction.

The FT-IR results of the $\mathrm{CO}$ adsorption of the samples after hydrogen treatment at $200{ }^{\circ} \mathrm{C}$ are shown in Fig. 5 . Small amounts of $\mathrm{CO}$ uptake were noted for the $\mathrm{Pt}-\mathrm{Mo} / \mathrm{H}-$ ZSM-5 catalysts as shown by pulse $\mathrm{CO}$ chemisorption in Table 2 and these results are corroborated by the FT-IR results shown in Fig. 5. The intensity of the $\mathrm{CO}$ adsorbed on

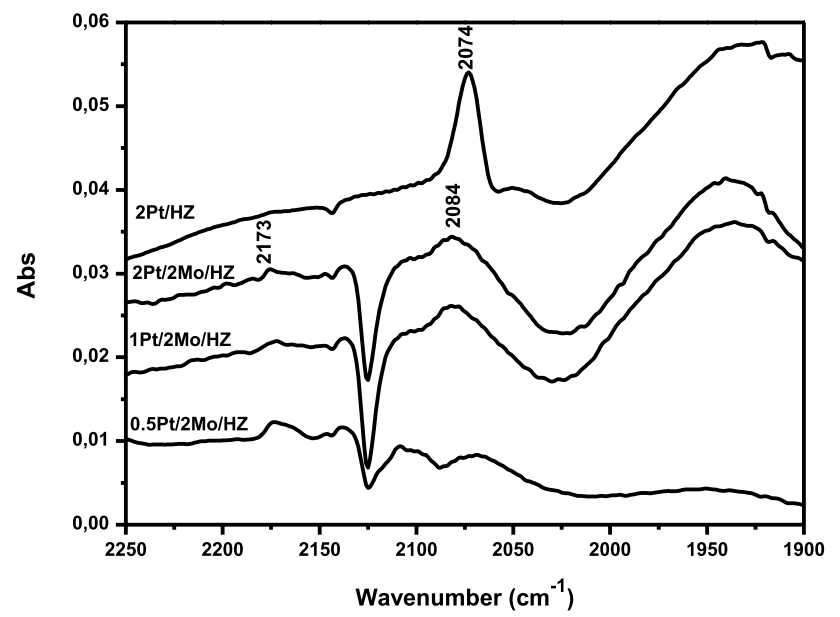

Fig. 5 FT-IR spectra of the CO adsorption on the Pt/Mo/HZSM-5 catalysts reduced at $200{ }^{\circ} \mathrm{C}$ for $1 \mathrm{~h}$ the metallic platinum species increased with an increase in platinum loading as shown by the broad bands at $2084 \mathrm{~cm}^{-1}$. However, the spectrum of the $2 \mathrm{Pt} / \mathrm{H}-\mathrm{ZSM}-5$ molybdenum free catalyst (Fig. 5b) shows a clearly defined band at $2074 \mathrm{~cm}^{-1}$ with high intensity. The intensity of the band is associated with the amount or concentration of $\mathrm{CO}$ adsorbed on the metallic platinum species. The shift in band position is due to the electronic interaction between platinum and molybdenum. The band at $2173 \mathrm{~cm}^{-1}$ is ascribed to $\mathrm{CO}$ adsorbed on unreduced $\mathrm{Mo}^{4+}$ species and the intensity of the band decreases with an increase in platinum loading.

\section{Catalytic results}

\section{Effect of platinum loading on the MDA reaction}

The effect of platinum loading on the catalytic performance of Mo/H-ZSM-5 zeolite catalysts on the MDA reaction was investigated. Reactions were performed at $700{ }^{\circ} \mathrm{C}$ using a mixture of methane and $\arg$ on $\left(90 \% \mathrm{CH}_{4}\right.$, balance Ar) flowing at $13.5 \mathrm{~mL} / \mathrm{min}$. Figure 6 a shows the effect of platinum loading on the methane conversion after $245 \mathrm{~min}$ on-stream. The catalytic conversion of methane over the $\mathrm{Mo} / \mathrm{H}-\mathrm{ZSM}-5$ catalyst was $7.5 \%$ and upon addition of 0.5 wt. $\%$ platinum the conversion of methane was recorded to be $7.2 \%$. Further increase of the platinum loading led to a linear decrease in methane conversion reaching a minimum of $4.7 \%$ for a $2 \mathrm{wt} . \%$ platinum-containing catalyst. A decrease in methane conversion observed when the platinum loading was increased from 0.5 to $2 \mathrm{wt} . \%$ may be attributed to the hydrogenolysis activity of platinum, which is more pronounced with an increase in platinum loading. Platinum group metals are well known to promote hydrogenation of the reaction intermediates of lower carbon number into methane [51]. The influence of platinum loading on
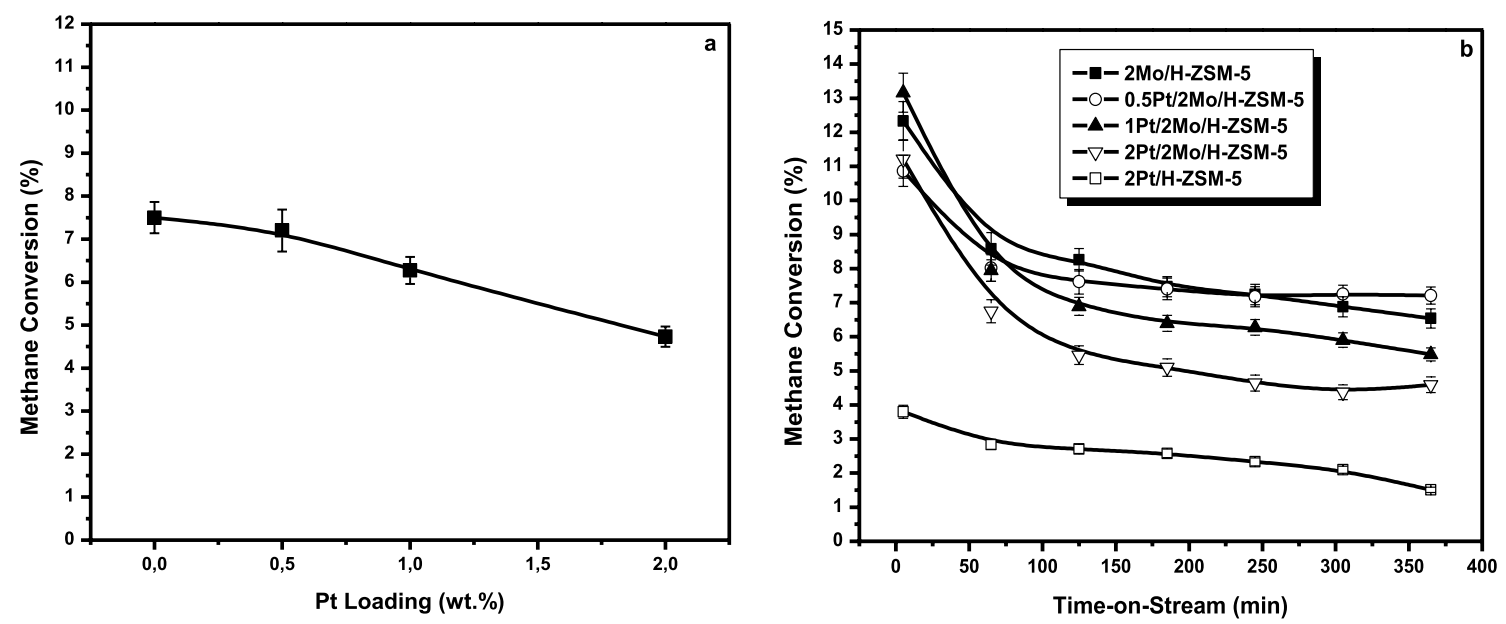

Fig. 6 The effect of platinum on the catalytic conversion of methane at $700{ }^{\circ} \mathrm{C}$ 
the catalyst stability of the Mo/H-ZSM-5 zeolite catalysts was studied at $700{ }^{\circ} \mathrm{C}$ for $6 \mathrm{~h}$ (Fig. 6b). From the results, it can be observed that the high initial conversions of methane were followed by a gradual decrease with increase in TOS that reached a steady-state after 168 min on-stream. A decrease in methane conversion with increase in TOS was observed with the $2 \% \mathrm{Mo} / \mathrm{H}-\mathrm{ZSM}-5$ zeolite catalyst. This can be attributed to the rapid deactivation of the catalyst which is caused by coke accumulation on the catalyst during the reaction [52]. Coke anchors on the active sites rendering them inactive [53]. This prevents methane from accessing the active sites; hence the decrease in methane conversion with increase in TOS was observed. The addition of platinum enhanced the stability of the catalyst with the $0.5 \mathrm{wt} . \%$ platinum loaded catalyst showing good catalytic performance when compared with the higher platinum loaded catalysts. Methane conversions between 7 and $11 \%$ were observed for the $0.5 \mathrm{wt} . \%$ Pt loaded catalyst while the 1 and $2 \mathrm{wt}$.\% platinum loaded catalysts showed conversions of between 4 and $11 \%$ values. Low methane conversions (i.e. below $2 \%$ ) were observed for the $2 \mathrm{Pt} / \mathrm{H}-\mathrm{ZSM}-5$ catalyst. This is attributed to the absence of molybdenum species responsible for activating methane into reactive intermediates. In this work, a decrease in methane conversion with increase in total metal content was observed. However, upon the addition of platinum a decrease in the deactivation rate was observed. It has been reported that the presence of noble metals decreases the amount of carbonaceous deposits formed during the MDA reaction by hydrogenolysis of coke $[54,55]$.

Figure 7a shows the effect of platinum loading on the aromatic and coke selectivity of Mo/H-ZSM-5 and Pt/Mo/HZSM-5 catalysts with various platinum loadings. The aromatic selectivity of platinum loaded Mo/H-ZSM- 5 catalysts is between 60 and $90 \%$, with the $0.5 \mathrm{wt} . \%$ platinum catalyst possessing a high aromatic selectivity. A gradual decrease in the aromatic selectivity with TOS was observed when the platinum loading was increased from 0.5 to $2 \mathrm{wt} . \%$. This decrease can be attributed to a decrease in the concentration of Brønsted acid sites with increase in total metal loading as shown by the $\mathrm{NH}_{3}$-TPD results in Fig. 2. The decrease in the aromatic selectivity is compensated for by the increase in the coke selectivity with increase in TOS. This increase in coke selectivity can be attributed to the decrease in surface area and pore volume as the total metal loading was increased. The formation of benzene was significantly high (about 80\%) for the catalysts with $0.5 \mathrm{wt}$ \% platinum loading and remained stable with increase in TOS (Fig. 7b). From the results presented in Table 3, we observed a decrease in benzene selectivity with increase in platinum loading while the selectivity towards toluene and naphthalene increased. This can be attributed to an increase in the alkylation of benzene with increase in platinum concentration $[56,57]$.
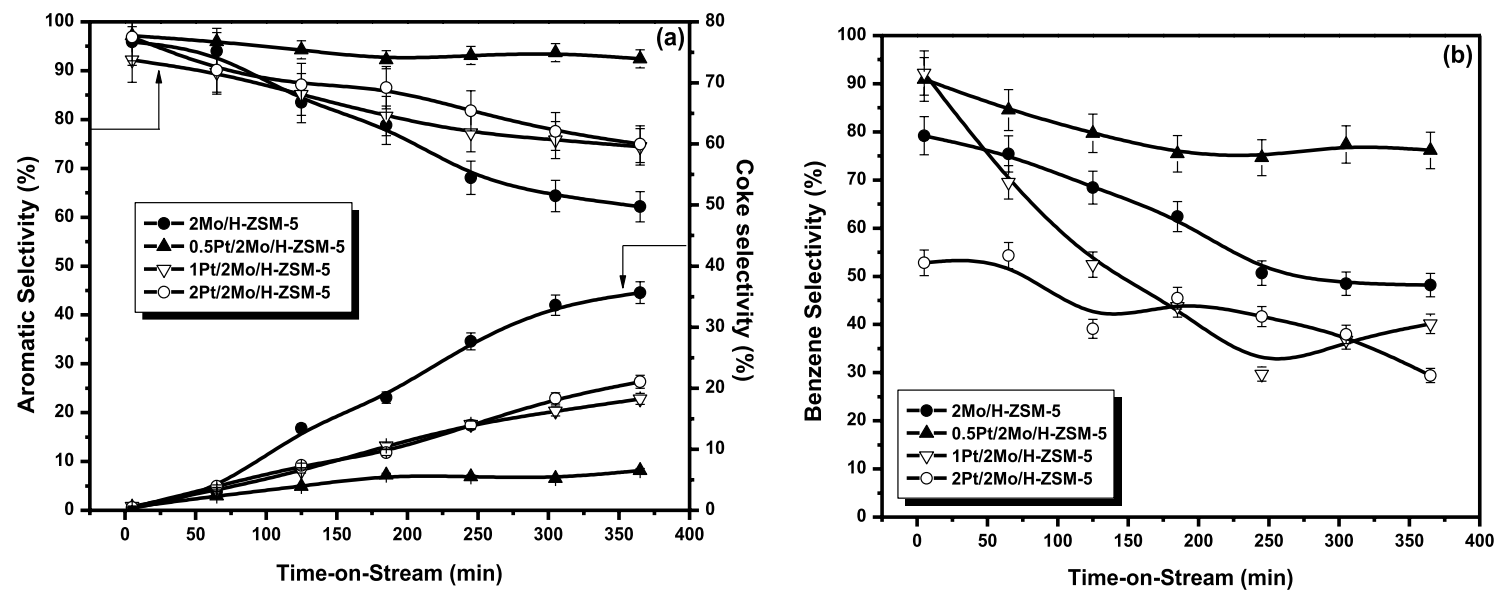

Fig. 7 Aromatic, coke selectivities (a) and benzene selectivities (b) of Mo/H-ZSM-5 and Pt/H-ZSM-5 with various platinum loadings (i.e. between 0.5 and 2 wt.\%) plotted against time-on-stream

Table 3 Product selectivity of Mo/H-ZSM-5 and Pt/Mo/HZSM-5 zeolite catalysts taken at TOS of $245 \mathrm{~min}$

\begin{tabular}{|c|c|c|c|c|c|c|c|}
\hline \multirow{2}{*}{$\begin{array}{l}\text { Pt Loading } \\
\text { (wt.\%) }\end{array}$} & \multirow{2}{*}{$\begin{array}{l}\text { Conversion } \\
(\%)\end{array}$} & \multicolumn{6}{|c|}{ Percentage product selectivity } \\
\hline & & $\mathrm{C}_{2 \text { 's }}$ & Benzene & Toluene & Naphthalene & Aromatics & Coke \\
\hline 0 & 7.5 & 2.3 & 50.5 & 7.4 & 10.1 & 68.0 & 29.7 \\
\hline 0.5 & 7.2 & 1.4 & 70.7 & 4.7 & 13.7 & 89.1 & 9.5 \\
\hline 1.0 & 6.2 & 8.7 & 59.7 & 3.4 & 14.2 & 77.3 & 14.0 \\
\hline 2.0 & 4.7 & 4.1 & 51.6 & 5.8 & 14.4 & 71.8 & 24.1 \\
\hline
\end{tabular}


Hence, the addition of platinum to Mo/H-ZSM-5 favored the formation of toluene and naphthalene.

Results of the effect of platinum loading on the product selectivity to hydrocarbons over platinum loaded $\mathrm{Mo} / \mathrm{H}-$ ZSM-5 zeolite catalyst are shown in Table 3. Catalysts were compared at similar conversions of methane taken after 245 min on stream. The results show that the product distribution in affected by the levels of platinum added onto the $\mathrm{Mo} / \mathrm{H}-\mathrm{ZSM}-5$ catalyst. The effect of platinum is noticeable at a $0.5 \mathrm{wt} . \%$ platinum loading. Here the selectivity towards benzene increased from 50 to $70 \%$ and the total aromatic selectivity increased by $20 \%$ reaching a maximum of $89 \%$. An increase in platinum loading led to a decrease in benzene selectivity, reaching a minimum of $52 \%$ for the $2 \mathrm{wt} . \%$ platinum loaded catalyst. The selectivity towards the heavy toluene and naphthalene was hardly affected by the increase in platinum loading. The selectivity towards toluene was between 4 and $6 \%$ and naphthalene increased from 10 to $14 \%$. Furthermore, a noticeable effect of platinum loading on the coke selectivity was observed with the coke selectivity decreasing from 30 to $9.5 \%$ upon addition of 0.5 wt. $\%$ of platinum. However, an increase in platinum led to undesired results and the coke selectivity increased to $24 \%$. These results were confirmed by the TGA results presented in Fig. 8 below.

The results of TGA and DTG measurements of the $\mathrm{Mo} / \mathrm{H}$ ZSM-5 and the platinum modified Mo/H-ZSM-5 zeolite catalysts with platinum loadings between 0.5 and $2 \mathrm{wt} . \%$ are shown in Fig. 8a, b respectively.

Catalyst deactivation by coke deposition on Mo/H-ZSM-5 during the MDA reaction remains a prevalent problem as this reaction is only feasible at high reaction temperatures. The most pronounced problems associated with coke are catalyst deactivation which is due to the formation of coke on the active sites of the catalysts, blocking the reactants from accessing the reactive sites of the catalyst. In H-ZSM-5 coke is formed on the Brønsted acid sites. On the other hand, coke can alter the geometry of the channels and pores of the zeolite which can then lead to a change in the product selectivity of the catalyst $[58,59]$. Heavy aromatic compounds formed in the channels will now be intermediates for the formation of polyaromatic coke. The sizes of these intermediates prevent them from diffusing through the coke-modified channels of the zeolite [59, 60]. The TGA and DTG results show a study of the effect of platinum on the amount of coke deposited during the MDA reaction at $700{ }^{\circ} \mathrm{C}$ after $6 \mathrm{~h}$. From the TGA profiles presented in Fig. 8a and Table 4 , it can be noted that over $120 \mathrm{mg} / \mathrm{g}$ of coke was deposited on the Mo/H-ZSM-5 catalyst. Addition of platinum led to a decrease in the coke deposited on the $\mathrm{Pt} / \mathrm{Mo} / \mathrm{H}$ ZSM-5 catalysts with various platinum loadings. For the 0.5

Table 4 TGA and DTG results of coked Mo/H-ZSM-5 and Pt/Mo/HZSM-5 with various platinum loadings

\begin{tabular}{llll}
\hline Catalyst & $\begin{array}{l}\text { Amount of } \\
\text { Coke (mg/g } \\
\text { cat.) }\end{array}$ & $\begin{array}{l}\text { Decomposition } \\
\text { Temperature } \\
(\mathrm{oC})\end{array}$ & $\begin{array}{l}\text { Decomposition } \\
\text { Temperature } \\
(\mathrm{oC})\end{array}$ \\
\hline $\begin{array}{l}\text { 2Mo/H-ZSM-5 } \\
\text { 0.5Pt/2Mo/H- } \\
\text { ZSM-5 }\end{array}$ & 121 & 583 & 660 \\
$\begin{array}{l}\text { 1Pt/2Mo/H- } \\
\text { ZSM-5 }\end{array}$ & 45 & 529 & 634 \\
$\begin{array}{c}2 \mathrm{Pt} / 2 \mathrm{Mo} / \mathrm{H}- \\
\mathrm{ZSM}-5\end{array}$ & 75 & 538 & 622 \\
\begin{tabular}{l} 
2Pt/H-ZSM-5 \\
\hline
\end{tabular} & 63 & 542 & 607 \\
\hline
\end{tabular}
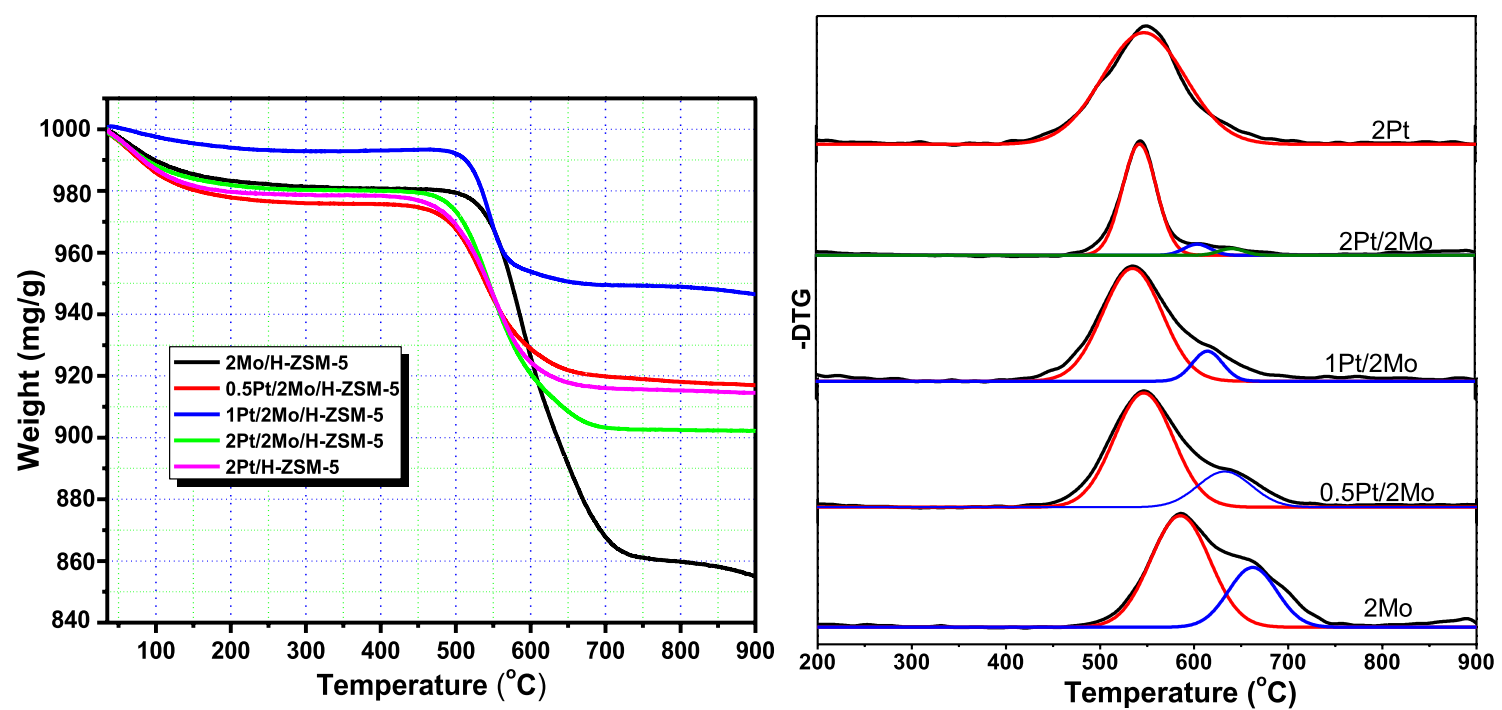

Fig. 8 TGA (a) and DTG (b) profiles of coked Mo/H-ZSM-5, Pt/Mo/H-ZSM-5 and Pt/H-ZSM-5 zeolite catalysts after MDA reactions at $700{ }^{\circ} \mathrm{C}$ 
wt.\% platinum catalyst, $54 \mathrm{mg} / \mathrm{g}$ of coke was deposited and upon increasing the platinum loading to 1 and $2 \mathrm{wt} . \% 45$ and $75 \mathrm{mg} / \mathrm{g}$ of coke deposition was observed respectively. These results show that the addition of platinum reduces the amount of coke deposition by $50 \%$ and this is in agreement with the product selectivity results presented in Table 3 . The suppression of coke is attributed to the presence of platinum which aids in the hydrogenation capability in the MDA reaction [61]. The hydrogen produced during the reaction will be adsorbed onto the platinum species which then dissociates into hydrogen atoms. These hydrogen atoms will then migrate onto the coke interface and hydrogenate the polyaromatic hydrocarbon into lighter hydrocarbons. The DTG profiles showed two well-defined peaks which can be attributed to the decomposition of two different types of coke/ carbon formed during the MDA reaction. The first peak (at $583{ }^{\circ} \mathrm{C}$ ) is due to the oxidation of carbon that is associated with molybdenum and carbidic carbon in the molybdenum carbide while the second peak (at $660{ }^{\circ} \mathrm{C}$ ) is due to the oxidation of aromatic carbon formed on the Brønsted acid sites $[18,62,63]$. The presence of platinum catalyzes the oxidation of the carbonaceous deposit and this leads to a decrease of the oxidation temperature of both forms of coke (i.e. on molybdenum and Brønsted acid sites). This can be attributed to the decrease in the stability of coke formed during the MDA over the platinum modified catalysts caused by the hydrogenation of coke ${ }^{\circ} \mathrm{C}$ curring simultaneously with the aromatization reaction [64]. Other reasons have been reported for the decrease in oxidation temperature of the DTG peaks associate with carbon. For example, platinum is a good oxidation catalyst and could decrease the oxidation temperatures of coke/carbon observed on the platinum loaded Mo/H-ZSM-5 zeolite catalysts [65, 66]. Only a single oxidation peak at $548{ }^{\circ} \mathrm{C}$ oxidation temperature was observed for $2 \mathrm{Pt} / \mathrm{H}-\mathrm{ZSM}-5$. This was assigned to the oxidation of coke deposited on the Brønsted acid sites; the absence of the second peak is due to the absence of $\mathrm{Mo}_{2} \mathrm{C}$ in the catalyst.

\section{Effect of noble metals (i.e. Pt, Pd and Ru) on the MDA reaction}

A comparison study was performed to investigate the influence of other noble metals on the MDA reaction over a Mo/H-ZSM-5 zeolite catalyst. Palladium and ruthenium were chosen as addition metals of interest. These noble metal catalysts were prepared by impregnation of $\mathrm{Mo} / \mathrm{H}-$ ZSM-5 with 0.5 wt.\% of the noble metals which were calcined at $500{ }^{\circ} \mathrm{C}$ for $6 \mathrm{~h}$. The MDA reaction was performed at $700{ }^{\circ} \mathrm{C}$ for $6 \mathrm{~h}$. Prior to the reaction the catalysts were treated with nitrogen at $700{ }^{\circ} \mathrm{C}$ for $1 \mathrm{~h}$ and exposed to methane for 30 min. Figure 9 shows the comparison results for the methane conversion over Mo/H-ZSM-5, Pt/Mo/H-ZSM-5, Pd/

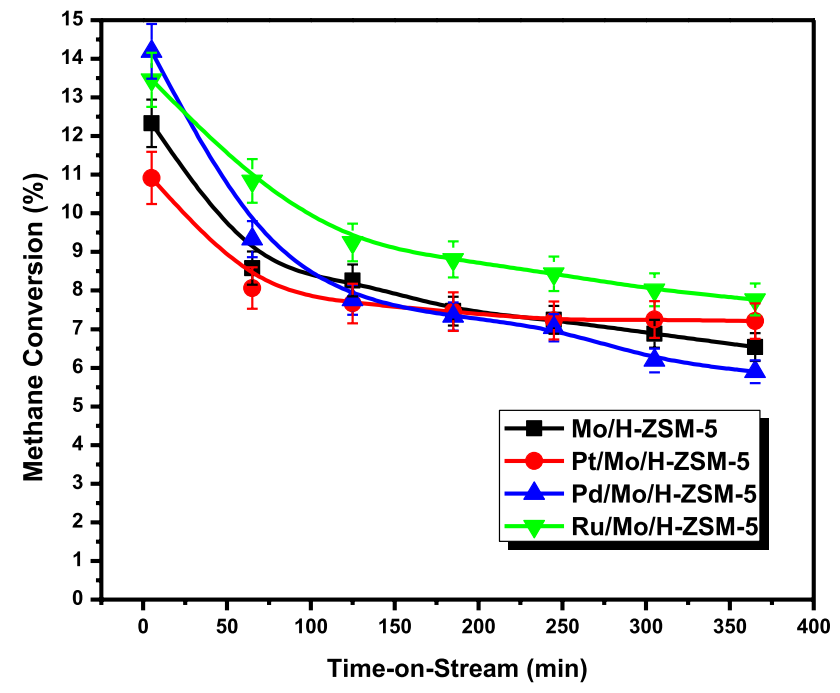

Fig. 9 The catalytic conversion of methane as a function of time-onstream over noble metal modified $2 \mathrm{Mo} / \mathrm{H}-\mathrm{ZSM}-5$ zeolite catalysts with a of $0.5 \mathrm{wt} . \%$ loading of the noble metal

Mo/H-ZSM-5 and Ru/Mo/H-ZSM-5 catalysts. The conversion of methane at low TOS (i.e. first two data points) is to be noted. After 5 and 65 min on-stream, a high methane conversion for the ruthenium and palladium Mo/H-ZSM-5 catalysts was observed. This can be attributed to the carbiding of molybdenum oxide or oxycarbide that might have during the incorporation of these noble metals as the carbided catalysts were exposed to the atmosphere. Addition of palladium and platinum to the Mo/H-ZSM-5 catalyst had a major effect on the catalytic activity of methane conversion over promoted Mo/H-ZSM-5 catalysts. An improvement in the catalytic activity was observed upon addition of ruthenium on to the Mo/H-ZSM-5 catalyst. Conversions of between 8 and 13\% were observed, with $13 \%$ being recorded at the start of the TOS measurements. The profile shows a steady exponential decrease in methane conversion with time on-stream. This decrease can be attributed to catalytic deactivation which is associated with coke deposition as mentioned above. Other factors have to be taken into account when employing noble metals in catalysis. Noble metals are well known to have a high hydrogenolysis activity towards hydrocarbons. During the reaction methyl radicals are formed on the molybdenum carbide species and if there is enough hydrogen formed in the presence of a noble metal it is possible for the methyl radical to react with the hydrogen atoms to form methane. Hence, the decrease in methane conversion might not only be associated with catalyst deactivation caused by coke formation during the MDA reaction over noble metal modified Mo/H-ZSM-5 catalysts.

Results of the effect of noble metals on the product selectivity of the Mo/H-ZSM-5 zeolite catalyst for the MDA reaction at $700{ }^{\circ} \mathrm{C}$ after $245 \mathrm{~min}$ on steam are shown in Table 5 . 
Table 5 Comparison results of the effect of noble metals on the MDA reaction and percentage product selectivities taken at $7 \%$ methane conversion after 245 min on-stream

\begin{tabular}{|c|c|c|c|c|c|c|c|}
\hline \multirow[t]{2}{*}{ Catalyst } & \multirow{2}{*}{$\begin{array}{l}\text { Conversion } \\
(\%)\end{array}$} & \multicolumn{6}{|c|}{ Percentage product selectivity } \\
\hline & & $\mathrm{C}_{2 \mathrm{~s}}$ & Benzene & Toluene & Naphthalene & Aromatics & Coke \\
\hline Mo & 7.5 & 2.3 & 50.5 & 7.4 & 10.1 & 70.3 & 29.7 \\
\hline $\mathrm{Pt} / \mathrm{Mo}$ & 7.2 & 1.4 & 70.7 & 4.7 & 13.7 & 89.1 & 9.5 \\
\hline $\mathrm{Pd} / \mathrm{Mo}$ & 7.0 & 1.1 & 65.6 & 9.0 & 15.5 & 90.1 & 8.8 \\
\hline $\mathrm{Ru} / \mathrm{Mo}$ & 8.5 & 1.8 & 60.8 & 6.5 & 25.1 & 92.4 & 5.8 \\
\hline
\end{tabular}

Catalysts were compared at $7 \%$ iso-conversion of methane taken after $245 \mathrm{~min}$ on-stream. From the results presented below, it is clear that addition of a noble metal to the Mo/HZSM-5 catalyst has an influence on the product distribution. Addition of a noble metal led to high aromatic selectivity and a decrease in coke selectivity. The results demonstrated that the ruthenium loaded Mo/H-ZSM-5 catalyst is a good catalyst and yields high aromatic selectivity (i.e. 92\%) and low selectivity to coke (i.e. 5.8\%). For the Mo/H-ZSM-5 catalyst, the selectivity to benzene was $50 \%$ and upon addition of noble metals, an increase in benzene was observed with the platinum loaded catalyst reaching an optimum of $70 \%$. The palladium and ruthenium promoters gave 66 and $61 \%$ selectivities respectively. Ruthenium loaded $\mathrm{Mo} / \mathrm{H}-$ ZSM-5 showed high selectivity towards naphthalene (25\%) when compared with the naphthalene selectivity of platinum (14\%) and palladium (16\%) catalysts. The low naphthalene selectivities observed for platinum and palladium may be attributed to the ability of the two metals to catalyze hydrogenolysis of heavy hydrocarbons in the presence of hydrogen [67-69]. The presence of platinum and palladium decreased the formation of naphthalene which was compensated by the high selectivity to benzene.

The effect of noble metals on the total amount of coke deposited during the MDA reaction at $700{ }^{\circ} \mathrm{C}$ was studied

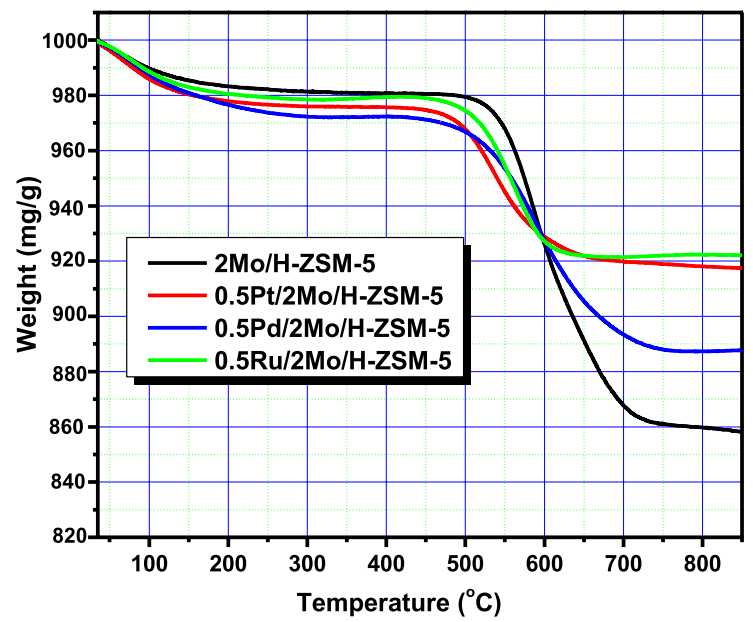

by thermal gravimetric measurements. The TGA and DTG results of the noble metal modified Mo/H-ZSM-5 zeolite catalysts are shown in Fig. 10a, b, espectively.

The amount of coke deposited on Mo/H-ZSM-5 catalyst was $121 \mathrm{mg} / \mathrm{g}$.cat and upon addition of a noble metal a decrease in the amount of coke was observed. The platinum and ruthenium promoted catalysts gave 54 and $59 \mathrm{mg} / \mathrm{g}$ coke deposit. From the TGA profile of the palladium promoted catalyst, $86 \mathrm{mg} / \mathrm{g}$ of coke deposit was observed. The decrease in the amount of coke deposited on the noble metal catalysts is associated with the hydrogenolysis of heavy aromatic compounds which contribute towards coke formation when they condense on the Brønsted acid sites. The DTG profile of Mo/H-ZSM-5 catalyst showed two peaks at 584 and $660{ }^{\circ} \mathrm{C}$ oxidation temperatures associated with different types of coke. Upon addition of the noble metals a shift in the peak position was observed, with peaks shifting to lower oxidation temperatures. The decrease in the oxidation temperature of coke is due to the destabilization of coke during the MDA reaction at $700{ }^{\circ} \mathrm{C}$. The decrease in coke stability is caused by the hydrogenation of coke that might be taking place during the MDA reaction. The hydrogen produced during the MDA can be used to hydrogenate the coke formed and this leads to a decrease in the carbon to hydrogen ratio. The decrease in area under the deconvoluted

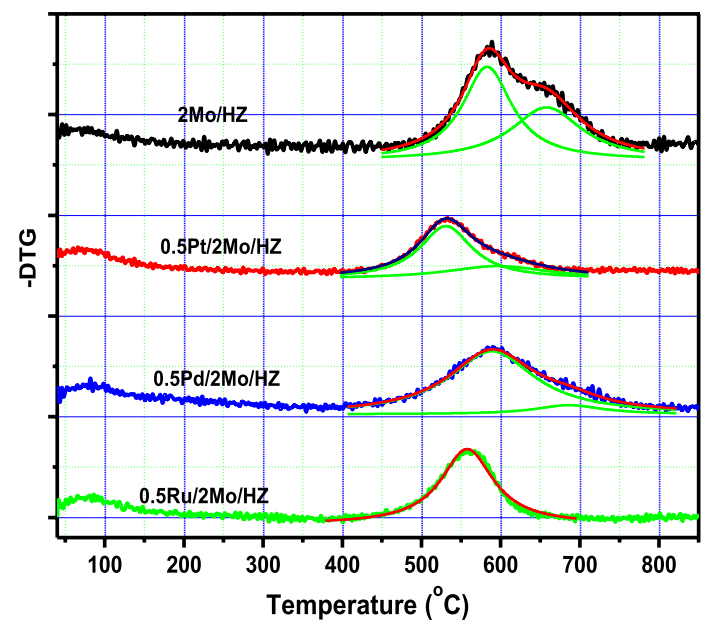

Fig. 10 TGA (a) and DTG (b) profiles of coked Mo/H-ZSM-5, Pt/Mo/H-ZSM-5 Pd/Mo/H-ZSM-5 and Ru/Mo/H-ZSM-5 zeolite catalysts after MDA reactions for $6 \mathrm{~h}$ at $700{ }^{\circ} \mathrm{C}$ 
curves is associated with the amounts of coke deposited on the active sites. The intensity of the peak appearing at high temperature decreased upon addition of the noble metals and for the ruthenium catalyst the peak is not visible. This can be attributed to the decrease in the amount of coke formed on the Brønsted acid site in the presence of a noble metal.

\section{Conclusions}

The MDA reaction over platinum modified Mo/H-ZSM-5 zeolite at $700{ }^{\circ} \mathrm{C}$ was successfully studied. The influence of platinum on the surface properties of molybdenum species was investigated by FT-IR CO adsorption and pulse chemisorption techniques. The FT-IR results showed the presence of various platinum cations in different oxidation states which are not detectable in TPR studies because of their stability. However, these cations are expected to have little significance in the MDA reaction as this reaction is performed at a high reaction temperature. The adsorption of $\mathrm{CO}$ on molybdenum carbide in the $\mathrm{Pt} / \mathrm{Mo}_{2} \mathrm{C} / \mathrm{H}-\mathrm{ZSM}-5$ zeolite catalysts containing low Mo loadings is still a mystery. In the FT-IR spectra, no band corresponding with CO adsorbed on $\mathrm{Mo}_{2} \mathrm{C}$ was present. However, two bands at 2162 and $2174 \mathrm{~cm}^{-1}$ were identified, which are associated with $\mathrm{CO}$ adsorbed on $\mathrm{Mo}^{4+}$ species in the catalyst. The shift in band position from 2162 to $2174 \mathrm{~cm}^{-1}$ is due to $\mathrm{Mo}-\mathrm{Pt}$ interaction after the catalysts were reduced with hydrogen at $200{ }^{\circ} \mathrm{C}$. The addition of platinum to the Mo/H-ZSM-5 zeolite catalyst enhanced the catalyst stability of the $\mathrm{Mo} / \mathrm{H}-$ ZSM-5 catalyst during the MDA reaction. This was attributed to the decrease in the deactivation rate and reduction of coke deposits caused by the presence of platinum species in the proximity of molybdenum and Brønsted acid sites. High aromatic selectivities (i.e. 90\%) were observed when a 0.5 wt.\% platinum loaded catalyst was used, with benzene being the most prominent product. The TGA results revealed that the presence of platinum in Mo/H-ZSM-5 led to a decrease in coke deposition by $50 \%$. The addition of noble metals to the Mo/H-ZSM-5 catalyst significantly affected the methane conversion but the catalytic stability was enhanced. The ruthenium promoted catalyst showed a higher methane conversion than found for the un-promoted and the Pt and Pd promoted catalysts. Only a small amount of deactivation was noted. The overall effect of a noble metal addition to the Mo/H-ZSM-5 catalyst was to modify the aromatic selectivity. The selectivity to aromatics was enhanced by $20 \%$ for the promoted catalysts, with an aromatic selectivity of $90 \%$ attained. Benzene selectivity of about $60 \%$ was observed for ruthenium and palladium promoted catalysts while the total aromatic selectivity was maintained at $90 \%$. The presence of a noble metal favored the formation of naphthalene with $14 \%, 16 \%$ and $25 \%$ observed for $\mathrm{Pt}, \mathrm{Pd}$ and $\mathrm{Ru}$ promoted catalyst, respectively. Low selectivities to coke were observed for the promoted Mo/H-ZSM-5 zeolite catalysts. This was confirmed by TGA results which showed a $50 \%$ reduction in the carbon deposit on the promoted $\mathrm{Mo} / \mathrm{H}-$ ZSM-5 catalyst.

Acknowledgements We wish to thank the National Research Foundation (NRF) South Africa, University of Aberdeen (Scotland, UK) and the University of the Witwatersrand for financial support.

Open Access This article is licensed under a Creative Commons Attribution 4.0 International License, which permits use, sharing, adaptation, distribution and reproduction in any medium or format, as long as you give appropriate credit to the original author(s) and the source, provide a link to the Creative Commons licence, and indicate if changes were made. The images or other third party material in this article are included in the article's Creative Commons licence, unless indicated otherwise in a credit line to the material. If material is not included in the article's Creative Commons licence and your intended use is not permitted by statutory regulation or exceeds the permitted use, you will need to obtain permission directly from the copyright holder. To view a copy of this licence, visit http://creativecommons.org/licenses/by/4.0/.

\section{References}

1. Wang L, Tao L, Xie M, Xu G, Huang J, Xu Y (1993) Dehydrogenation and aromatization of methane under non-oxidizing conditions. Catal Lett 21:35-41

2. Wang L, Xu Y, Wong ST, Cui W, Guo X (1997) Activity and stability enhancement of MoHZSM-5-based catalysts for methane non-oxidative transformation to aromatics and $\mathrm{C} 2$ hydrocarbons: effect of additives and pretreatment conditions. Appl Catal A Gen 152:173-182

3. Xu Y, Lin L (1999) Recent advances in methane dehydro-aromatization over transition metal ion-modified zeolite catalysts under non-oxidative conditions. Appl Catal A Gen 188(1-2):53-67

4. Honda K, Chen X, Zhang ZG (2008) Preparation of highly active binder-added $\mathrm{MoO}_{3} / \mathrm{HZSM}-5$ catalyst for the non-oxidative dehydroaromatization of methane. Appl Cat A Gen 351:122-130

5. Honda K, Yoshida T, Zhang Z-G (2003) Methane dehydroaromatization over Mo/HZSM-5 in periodic $\mathrm{CH}_{4}-\mathrm{H}_{2}$ switching operation mode. Catal Commun 4:21-26

6. Sobalık Z, Tvarůžková Z, Wichterlova B, Fila V, Špatenka Š (2003) Acidic and catalytic properties of Mo/MCM-22 in methane aromatization: an FTIR study. Appl Catal A Gen 253:271-282

7. Xu Y, Bao X, Lin L (2003) Direct conversion of methane under nonoxidative conditions. J Catal 216:386-395

8. Xie M-S, Yang X, Chen W-H, Tao L-X, Wang X-L, Xu G-F, Wang L-S, Xu Y-D, Liu S-T, Guo X-X (1997) Stud Surf Sci Catal 105: 869-876

9. Tshabalala TE, Coville NJ, Scurrell MS (2016) Methane dehydroaromatization over modified $\mathrm{Mn} / \mathrm{H}-\mathrm{ZSM}-5$ zeolite catalysts: effect of tungsten as a secondary metal. Catal Commun 78:37-43

10. Zeng JL, Xiong ZT, Zhang HB, Lin GD, Tsai KR (1998) Nonoxidative dehydrogenation and aromatization of methane over W/ HZSM-5-based catalysts. Catal Lett 53:119-124

11. Liu B, Yang Y, Sayari A (2001) Non-oxidative dehydroaromatization of methane over Ga-promoted Mo/HZSM-5-based catalysts. Appl Catal A Gen 214:95-102 
12. Lai Y, Veser G (2016) The nature of the selective species in FeHZSM-5 for non-oxidative methane dehydroaromatization. Catal Sci Technol 6:5440-5452

13. Szöke A, Solymosi F (1996) Selective oxidation of methane to benzene over K2MoO4/ZSM-5 catalysts. Appl Catal A Genl 142:361-374

14. Solymosi F, Cserényi J, Szöke A, Bánsági T, Oszkó A (1997) Aromatization of methane over supported and unsupported mobased catalysts. J Catal 165:150-161

15. Jiang H, Wang L, Cui W, Xu Y (1999) Study on the induction period of methane aromatization over Mo/HZSM-5: partial reduction of Mo species and formation of carbonaceous deposit. Catal Lett 57:95-102

16. Wang D, Lunsford JH, Rosynek MP (1996) Catalytic conversion of methane to benzene over Mo/ZSM-5. Top Catal 3:289-297

17. Wang D, Lunsford JH, Rosynek MP (1997) Characterization of a Mo/ZSM-5 catalyst for the conversion of methane to benzene. J Catal 169:347-358

18. Weckhuysen BM, Rosynek MP, Lunsford JH (1998) Characterization of surface carbon formed during the conversion of methane to benzene over Mo/H-ZSM-5 catalysts. Catal Lett 52:31-36

19. Weckhuysen BM, Wang D, Rosynek MP, Lunsford JH (1998) Conversion of methane to benzene over transition metal Ion ZSM-5 zeolites. J Catal 175:347-351

20. Ha VTT, Tiep LV, Meriaudeau P, Naccache C (2002) Aromatization of methane over zeolite supported molybdenum: active sites and reaction mechanism. J Mol Catal A Chem 181:283-290

21. Tan PL, Wong KW, Au CT, Lai SY (2003) Effects of Co-fed $\mathrm{O}_{2}$ and $\mathrm{CO}_{2}$ on the deactivation of Mo/HZSM-5 for methane aromatization. Appl Catal A Gen 253:305-316

22. Ma D, Shu Y, Cheng M, Xu Y, Bao X (2000) On the induction period of methane aromatization over mo-based catalysts. J Catal 194:105-114

23. Liu S, Wang L, Ohnishi R, Lchikawa M (2000) Bifunctional catalysis of Mo/HZSM-5 in the dehydroaromatization of methane with $\mathrm{CO} / \mathrm{CO}_{2}$ to benzene and naphthalene. Kinet Catal 41:132-144

24. Masiero S, Marcilio N, Perez-Lopez O (2009) Aromatization of methane over Mo-Fe/ZSM-5 catalysts. Catal Lett 131:194-202

25. Ohnishi R, Liu S, Dong Q, Wang L, Ichikawa M (1999) Catalytic dehydrocondensation of methane with $\mathrm{CO}$ and $\mathrm{CO}_{2}$ toward benzene and naphthalene on Mo/HZSM-5 and Fe/Co-modified Mo/ HZSM-5. J Catal 182:92-103

26. Shu Y, Xu Y, Wong S-T, Wang L, Guo X (1997) Promotional effect of $\mathrm{Ru}$ on the dehydrogenation and aromatization of methane in the absence of oxygen over Mo/HZSM-5 catalysts. J Catal 170:11-19

27. Chen LY, Lin LW, Xu ZS, Li XS, Zhang T (1995) Dehydro-oligomerization of Methane to ethylene and aromatics over molybdenum/HZSM-5 Catalyst. J Catal 157:190-200

28. Browning LC, Emmett PH (1952) Equilibrium measurements in the Mo-C-H system. J Am Chem Soc 74:4773-4774

29. Job N, Pereira MFR, Lambert S, Cabiac A, Delahay G, Colomer J-F, Marien J, Figueiredo JL, Pirard J-P (2006) Highly dispersed platinum catalysts prepared by impregnation of texture-tailored carbon xerogels. J Catal 240:160-171

30. Lin SD, Vannice MA (1993) Hydrogenation of aromatic hydrocarbons over supported Pt catalysts I. Benzene hydrogenation. J Catal 143:539-553

31. Abdelsayed V, Smith MW, Shekhawat D (2015) Investigation of the stability of Zn-based HZSM-5 catalysts for methane dehydroaromatization. Appl Catal A Gen 505:365-374

32. Wang Y, Zhao W, Li Z, Wang H, Wu J, Li M, Zhao Y (2015) Application of mesoporous ZSM-5 as a support for FischerTropsch cobalt catalysts. J Porous Mater 22:339-345
33. Liang J, Li H, Zhao S, Guo W, Wang R, Ying M (1990) Characteristics and performance of SAPO-34 catalyst for methanol-to-olefin conversion. Appl Catal 64:31-40

34. Hidalgo CV, Itoh H, Hattori T, Niwa M, Murakami Y (1984) Measurement of the acidity of various zeolites by temperatureprogrammed desorption of ammonia. J Catal 85:362-369

35. Chakarova K, Mihaylov M, Hadjiivanov K (2005) FTIR spectroscopic study of $\mathrm{CO}$ adsorption on $\mathrm{Pt}-\mathrm{H}-\mathrm{ZSM}-5$. Microporous Mesoporous Mater 81:305-312

36. Chakarova K, Mihaylov M, Hadjiivanov K (2005) Polycarbonyl species in Pt/H-ZSM-5: FTIR spectroscopic study of $12 \mathrm{CO}$ 13CO co-adsorption. Catal Commun 6:466-471

37. Chakarova K, Hadjiivanov K, Atanasova G, Tenchev K (2007) Effect of preparation technique on the properties of platinum in NaY zeolite: a study by FTIR spectroscopy of adsorbed CO. J Mol Catal A Chem 264 270-279

38. Barshad Y, Zhou X, Gulari E (1985) Carbon monoxide oxidation under transient conditions: a Fourier-transform infrared transmission spectroscopy study. J Catal 94(1):128-141

39. Ryczkowski J (2001) IR spectroscopy in catalysis. Catal Today 68:263-381

40. Riguetto BA, Damyanova S, Gouliev G, Marques CMP, Petrov L, Bueno JMC (2004) Surface behavior of alumina-supported Pt catalysts modified with cerium as revealed by X-ray diffraction, $\mathrm{X}$-ray photoelectron spectroscopy, and fourier transform infrared spectroscopy of CO adsorption. J Phys Chem B 108:5349-5358

41. Hollins $P$ (1992) The influence of surface defects on the infrared spectra of adsorbed species. Surf Sci Rep 16:51-94

42. Tzou MS, Teo BK, Sachtler WMH (1988) Formation of Pt particles in Y-type zeolites: the influence of coexchanged metal cations. J Catal 113:220-235

43. Kubanek P, Schmidt HW, Spliethoff B, Schüth F (2005) Parallel IR spectroscopic characterization of $\mathrm{CO}$ chemisorption on $\mathrm{Pt}$ loaded zeolites. Microporous Mesoporous Mater 77:89-96

44. Chakarova K, Ivanova E, Hadjiivanov K, Klissurski D, Knözinger $\mathrm{H}$ (2004) Co-ordination chemistry of palladium cations in Pd-H-ZSM-5 as revealed by FTIR spectra of adsorbed and coadsorbed probe molecules (CO and NO). Phys Chem Chem Phys 6:3702-3709

45. Aegerter PA, Quigley WW, Simpson GJ, Ziegler DD, Logan JW, McCrea KR, Bussell ME (1996) Thiophene hydrodesulfurization over alumina-supported molybdenum carbide and nitride catalysts: adsorption sites, catalytic activities, and nature of the active surface. J Catal 164:109-121

46. Wu W, Wu Z, Liang C, Chen X, Ying P, Li C (2003) In situ FT-IR spectroscopic studies of $\mathrm{CO}$ adsorption on fresh Mo2C/Al2O3 catalyst. J Phys Chem B 107:7088-7094

47. Yang S, Li C, Xu J, Xin Q (1997) In situ probing of surface sites on supported molybdenumnitride catalyst by $\mathrm{CO}$ adsorption. Chem Commun 13:1247-1248

48. Decanio EC, Storm DA (1991) Determination of zero-valent molybdenum after moderate temperature reduction of aluminasupported catalysts. J Catal (US)130: 653-656

49. Raskó J, Kiss J (2003) Infrared study of the adsorption of CO and $\mathrm{CH} 3$ on silica-supported $\mathrm{MoO}_{3}$ and Mo2C catalysts. Appl Catal A Gen 253:427-436

50. Decanio EC, Storm DA (1991) Carbon monoxide adsorption by K/ $\mathrm{Co} / \mathrm{Rh} / \mathrm{Mo} / \mathrm{Al} 2 \mathrm{O} 3$ higher alcohols catalysts. J Catal 132:375-387

51. Calderón LA, Chamorro E, Espinal JF (2016) Mechanisms for homogeneous and heterogeneous formation of methane during the carbon-hydrogen reaction over zigzag edge sites. Carbon 102:390-402

52. Liu H, Li T, Tian B, Xu Y (2001) Study of the carbonaceous deposits formed on a Mo/HZSM-5 catalyst in methane dehydroaromatization by using TG and temperature-programmed techniques. Appl Catal A Gen 213:103-112

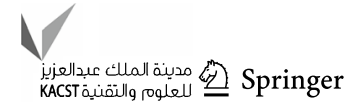


53. Tessonnier JP, Louis B, Rigolet S, Ledoux MJ, Pham-Huu C (2008) Methane dehydro-aromatization on Mo/ZSM-5: about the hidden role of Brønsted acid sites. Appl Catal A Gen 336:79-88

54. Jongpatiwut S, Sackamduang P, Rirksomboon T, Osuwan S, Resasco DE (2003) $n$-Octane aromatization on a Pt/KL catalyst prepared by vapor-phase impregnation. J Catal 218:1-11

55. Samanta A, Bai X, Robinson B, Chen H, Hu J (2017) Conversion of light alkane to value-added chemicals over ZSM-5/metal promoted catalysts. Ind Eng Chem Res 56(39):11006-11012

56. Todorova S, Su BL (2003) Propane as alkylating agent for benzene alkylation on bimetal Ga and Pt modified H-ZSM-5 catalysts: FTIR study of effect of pre-treatment conditions and the benzene adsorption. J Mol Catal A Chem 201:223-235

57. Yang F, Zhong J, Liu X, Zhu X (2018) A novel catalytic alkylation process of syngas with benzene over the cerium modified platinum supported on HZSM-5 zeolite. Appl Energy 226:22-30

58. Bai R, Song Y, Li Y, Yu J (2019) Creating hierarchical pores in zeolite catalysts. Trends Chem 1:601-611

59. Wang N, Hou Y, Sun W, Cai D, Chen Z, Liu L, Wei F (2019) Modulation of $b$-axis thickness within MFI zeolite: correlation with variation of product diffusion and coke distribution in the methanol-to-hydrocarbons conversion. Appl Catal B Environ 243:721-733

60. Nordvang EC, Borodina E, Ruiz-Martínez J, Fehrmann R, Weckhuysen BM (2015) Effects of coke deposits on the catalytic performance of large zeolite H-ZSM-5 crystals during alcohol-tohydrocarbon reactions as investigated by a combination of optical spectroscopy and microscopy. Chem Eur J 21: 17324-1733

61. Aboul-Gheit AK, Awadallah AE, El-Kossy SM, Mahmoud A-LH (2008) Effect of Pd or Ir on the catalytic performance of $\mathrm{Mo} / \mathrm{H}-$ ZSM-5 during the non-oxidative conversion of natural gas to petrochemicals. J Nat Gas Chem 17:337-343
62. Choudhary VR, Banerjee S, Panjala D (2002) Influence of temperature on the product selectivity and distribution of aromatics and $\mathrm{C} 8$ aromatic isomers in the conversion of dilute ethene over H-galloaluminosilicate (ZSM-5 type) zeolite. J Catal 205:398-403

63. Ma D, Wang D, Su L, Shu Y, Xu Y, Bao X (2002) Carbonaceous deposition on Mo/HMCM-22 catalysts for methane aromatization: a TP technique investigation. J Catal 208:260-269

64. Hoang TQ, Zhu X, Danuthai T, Lobban LL, Resasco DE, Mallinson RG (2010) Conversion of glycerol to alkyl-aromatics over zeolites. Energy Fuels 24:3804-3809

65. Bayraktar O, Kugler EL (2002) Characterization of coke on equilibrium fluid catalytic cracking catalysts by temperatureprogrammed oxidation. Appl Catal A Gen 233:197-213

66. Boufaden N, Pawelec B, Fierro JLG, López RG, Akkari R, Zina MS (2018) Hydrogen storage in liquid hydrocarbons: effect of platinum addition to partially reduced $\mathrm{Mo}-\mathrm{SiO}_{2}$ catalysts. Materi Chem Phys 209:188-199

67. Mouli KC, Sundaramurthy V, Dalai AK, Ring Z (2007) Selective ring opening of decalin with Pt-Ir on Zr modified MCM-41. Appl Catal A Gen 321:17-26

68. Garba MD, Galadima A (2018) Catalytic hydrogenation of hydrocarbons for gasoline production. J Phys Sci. https://doi.org/10. 21315/jps2018.29.2.10

69. Collett C, McGregor J (2016) Things go better with coke: the beneficial role of carbonaceous deposits in heterogeneous catalysis. Catal Sci Technol 6:363-378

Publisher's Note Springer Nature remains neutral with regard to jurisdictional claims in published maps and institutional affiliations. 